\title{
Sexuality in Older Adults (65+)-An Overview of the Recent Literature, Part 2: Body Image and Sexual Satisfaction
}

\author{
Bente Træen PhD , Ana Carvalheira , Ingela Lundin Kvalem , Aleksandar \\ Štulhofer, Erick Janssen, Cynthia A Graham PhD , Gert Martin Hald \& Paul \\ Enzlin
}

To cite this article: Bente Træen PhD , Ana Carvalheira, Ingela Lundin Kvalem , Aleksandar Štulhofer , Erick Janssen, Cynthia A Graham PhD , Gert Martin Hald \& Paul Enzlin (2016): Sexuality in Older Adults (65+)_An Overview of the Recent Literature, Part 2: Body Image and Sexual Satisfaction, International Journal of Sexual Health, DOI: $10.1080 / 19317611.2016 .1227012$

To link to this article: http://dx.doi.org/10.1080/19317611.2016.1227012

Accepted author version posted online: 14 Sep 2016.

Published online: 14 Sep 2016.

Submit your article to this journal $₫$

山 Article views: 18

View related articles $\nearrow$

View Crossmark data $\nearrow$ 


\title{
ACCEPTED MANUSCRIPT
}

\section{Sexuality in Older Adults (65+) —An Overview of the Recent Literature, Part 2: Body Image and Sexual Satisfaction}

\author{
Professor Bente Træen PhD (Corresponding Author) \\ Email: bente.traen@psykologi.uio.no \\ University of Troms $\varnothing$, Department of Psychology, Troms $\varnothing, 9037$ Norway \\ Professor Ana Carvalheira \\ Email: acarvalheira@ispa.pt \\ ISPA Instituto Universitário, Department of Clinical Psychology, Lisbon, Portugal
}

Dr Ingela Lundin Kvalem

Email: i.1.kvalem@psykologi.uio.no

University of Oslo, Department of Psychology, Oslo, Norway

Professor Aleksandar Štulhofer

Email: astulhof@ffzg.hr

University of Zagreb, Department of Sociology, Ivana Lucica 3, Zagreb, 10000 Croatia

Professor Erick Janssen

Email: erick.janssen@kuleuven.be

University of Leuven, Institute for family and sexuality studies, Leuven, Belgium 


\title{
ACCEPTED MANUSCRIPT
}

\author{
Dr Cynthia A Graham PhD \\ Email: C.A.Graham@soton.ac.uk \\ University of Southampton, Southampton, United Kingdom of Great Britain and Northern \\ Ireland \\ Dr Gert Martin Hald \\ Email: gertmartinhald@gmail.com \\ University of Copenhagen, Department of Public Health, Copenhagen, Denmark \\ Professor Paul Enzlin \\ Email: paul.enzlin@uzleuven.be \\ University of Leuven, Institute for family and sexuality studies, Leuven, Belgium
}

\begin{abstract}
Aim: the aim of the paper is to provide an overview of the literature published 2005-2015 on sexual satisfaction and body image in older adults.

Method: A narrative literature search using the PsycINFO database was conducted.

Results: Although women in general seem less satisfied with their bodies than men, particularly in sexual contexts, older women appear to be less vulnerable to body-related dissatisfaction than younger women. Despite the age-specific dynamics of sexual satisfaction and sexual well-being, which parallel age-related decrease in the frequency of sexual activity, research findings from
\end{abstract}




\section{ACCEPTED MANUSCRIPT}

different countries show that substantial proportions of aging men and women are satisfied with their sex life. There is some limited evidence that this proportion may be increasing across cohorts. Gender differences in factors that influence sexual satisfaction among older adults appear marginal.

Conclusion: Older age can affect sexual satisfaction on individual, interpersonal, and culturerelated levels. Future research in older adults' sexuality should focus on sexual well-being in women who are without partners, sexual satisfaction among aging LGBT individuals and couples, the relationship between religiosity and sexual satisfaction, and employ a comparative, cross-cultural approach. 


\section{ACCEPTED MANUSCRIPT}

\section{Introduction}

The right to sexual health throughout the lifespan is increasingly considered a human right (WAS, 1999) and research has consistently demonstrated important links between 1) sexuality and health and 2) sexuality and illness across the life span, including in old age. For many older adults, sexuality and sexual relations remain important, if not central, to their interpersonal and intimate relationships, as well as to their quality of life (Graugaard, Pedersen, $\&$ Frisch, 2012).

Older adults who report good health are more likely to be sexually active, be sexually active for a longer duration (Lindau \& Gavrilova, 2010), have more frequent sex, and experience higher sexual desire (Kontula \& Haavio-Mannila, 2009). Similarly, being in a sexual partnership, "with frequent sexual expression, having a good quality sex life, and being interested in sex" (Syme, 2014, p. 36) has been positively associated with health among middle-aged and older adults. Moreover, an active sex life has been associated with decreased pain sensitivity, lower mortality, lower levels of depression, and lower incidence of chronic airways diseases, and higher levels of relaxation, cardiovascular health, self-esteem, quality of life, and relationship satisfaction (Brody, 2010; Davidson et al., 2009; Graugaard et al., 2012; Heiman et al., 2011; Jannini et al., 2009; Syme, 2014). Higher levels of sexual satisfaction are positively associated with emotional closeness, intimate communication, and marital and relationship satisfaction (Byers, 2005; Rosen et al., 2015), which in turn are positively associated with health and illness prevention, treatment effects, and recovery as well as how effectively one manages to cope with chronic disease (DeLamater, 2012; Graugaard et al., 2012). Likewise, poor health and cardiovascular diseases, diabetes, gynaecological disease, skin diseases, chronic pain disorders, 


\section{ACCEPTED MANUSCRIPT}

and mental disorders have all been found to adversely affect sexual functioning, body image, energy levels, self-esteem, interpersonal engagement, and quality of life, which all in turn can negatively impact sexuality, sexual expression, and sexual satisfaction in older individuals (DeLamater, 2012; DeLamater \& Karraker, 2009; Graugaard et al., 2012).

With the "new" generation of older adults, attitudes and beliefs about sex are becoming increasingly more liberal (Schmidt \& Mattiesen, 2003; Slagsvold \& Strand, 2005; Syme, 2014) and the vast majority of older adults perceive sex as critical for a good relationship and quality of life (Fisher, 2010). In a large Danish sample of adults more than $90 \%$ reported that their sex life was of great importance to them and among older adults an inability to maintain a sex life was perceived as a threat to health as great as "complete loss of hearing" and "treatment indicated hypertension" (Graugaard et al., 2012). Also, although the ability to have sexual intercourse and experience sexual desire decreases with age, the enjoyment and happiness associated with intimacy, emotional closeness, and tenderness in sexual relations increases with age (Graugaard et al., 2012). Accordingly, the nature of the sexual relationship may undergo changes with age as a function of biological, psychological, social, and cultural factors; however, the self-perceived importance attached to sexuality in old age remains high and significant (DeLamater \& Karraker, 2009).

Given the above, sexuality in old age may no longer be perceived as a privilege for the few but a resource among the many. Accordingly, this article aims to provide an overview of the more recently published scientific literature on sexuality and the body, sexual satisfaction and socio-cultural aspects of sexuality in older adults. This knowledge could be used as a stepping stone to the enhancement of sexual health in older adults. Although previous overviews of the 


\section{ACCEPTED MANUSCRIPT}

literature exists (see e.g., DeLamater, 2012), this paper presents a more current perspective than previously using literature from January 2005 to July 2015. Compared to previous literature overviews, the paper also covers more specific topics, such as sexual orientation and body image.

\section{Method}

To obtain an overview of the literature, a narrative review of the literature was conducted in the database Ovid PsycINFO in cooperation with two librarians at a University library in Oslo (Grant \& Booth, 2009; The Norwegian Knowledge Centre for the Health Services, 2016). A narrative review is a less comprehensive method than a systematic review, typically involving a narrower search strategy, and a search of fewer databases. The chosen database, Ovid PsycINFO, has many overlaps with other popular databases, such as Medline. The literature search was conducted following selection criteria set by The Norwegian Knowledge Centre for the Health Services (2016). The search aimed at identifying literature on sexual behaviors and sexual wellbeing of persons aged 65 years or older published between 1 January 2005 and 1 July 2015 in English language peer-reviewed scholarly journals. Regarding study designs, both quantitative and qualitative studies, as well as review papers and meta-analyses, were included. Studies included epidemiological and clinical research from a medical as well as a psychological perspective.

Initially, each co-author developed a list of keywords related to his/her area of contribution. To systematize the literature search, thematic areas were identified from the list of keywords. In addition to the research question, the thesaurus of Psychological Index Terms and 


\section{ACCEPTED MANUSCRIPT}

keywords were used to guide the literature search that was performed in July 2015. These keywords and search terms were combined and an age limitation using PsycINFO's filter for the age group 65 years and over. The search was sensitive to different variants and endings of the word "sexual." In addition, the term was also treated as an adjective (sexual function, sexual desire, sexual satisfaction, etc.). At step 2, the selection was limited to studies published in English, from 2005 and onwards. Animal studies on sexuality were removed at steps 3 and 4 . The literature search resulted in 4,214 references, that were all made available to the contributing authors, both as Word- and EndNote files. Following the completion of the literature search, a research assistant sorted and categorized the references by topic so that each co-author would receive only the references including abstracts, related to their specific area of contribution (a number of references were classified as reporting on more than one area of interest). Once all authors received the list of references from the research assistant, each was instructed to read the abstracts and select all relevant papers. Based on their reading of abstracts, each co-author made the final selection of papers relevant for his/her area of contribution. Upon closer inspection, many of the listed references were found unrelated to this study topic. There was no record of the number of papers that were rejected or selected.

\section{Results}

\section{Body Image and Sexuality in Later Life}

The transition into older adulthood is accompanied by changes in body weight and shape. Although body weight tends to increase in midlife for many men and women, BMI starts to level off and decrease around 60-65 years of age, which is accompanied by changes in body shape due 


\section{ACCEPTED MANUSCRIPT}

to fat redistribution. Other examples of bodily markers of aging are loss of skin elasticity and thinner hair/hair loss (Gagne et al., 2012; Pearce, Thøgersen-Ntoumani, \& Duda, 2013).

Body image is defined as a person's "perceptions, thoughts and feelings about his or her body" (Grogan, 2008, p. 3), and the behavior in relation to the body (Cash, 2004). Body image is related to the importance of appearance to an individual, affected by factors such as physical appearance, degree of internalization of body ideal, interpersonal experiences, and social comparison processes (Cash, 2004). The body ideal in Western culture is youthful, slim, fit (or muscular for men), and without wrinkles, with an emphasis on physical attractiveness and sexual desirability (Hurd Clark, \& Korotchenko, 2011; Montemurro \& Gillien, 2012). The social value placed on attractiveness for women is thought to be a central factor in the large gender difference in body satisfaction generally found in this area of research. Body dissatisfaction, especially weight concerns, is so common in women it has been denoted "a normative discontent" (Rodin, Silberstein, \& Striegel-Moore, 1984). Although body satisfaction increases from adolescence to adulthood and tends to be stable in midlife and later life, women remain more dissatisfied with their body and appearance than men (Hurd Clark, \& Korotchenko, 2011; Roy \& Payette, 2012). Stability in body image may seem surprising considering that age-related changes in appearance, especially in women, move them further away from the cultural youthful body ideal. An explanation for this may be that both men and women place increasingly less importance on appearance and more on body functioning and health as they age (Hurd Clark, \& Korotchenko, 2011; Roy \& Payette, 2012). Another reason might be that older women are holding on to the body ideal from their youth (which was curvier than present cultural body ideals) (Hurd Clark, 2000). Since measures of body image do not commonly assess age-related body changes, such as 


\section{ACCEPTED MANUSCRIPT}

satisfaction with skin or changes in fat distribution, it is also possible that most research to date has failed to capture age-dependent changes in body image, or the factors and processes that influence it (Roy \& Payette, 2012).

Body image and sexual health has generally been studied in relation to the impact of body dissatisfaction on sexual functioning and satisfaction in younger women or in midlife. In several studies sexual satisfaction has been associated with different aspects of a positive body image and sexual attractiveness among these age groups (for review, see Woertman \& van den Brink, 2012). A possible mechanism for this association is that body shame, body surveillance, and self-consciousness during sexual activity will distract from focusing on sexual pleasure (Claudat \& Warren, 2014). There is less research on body image and sexuality in younger men, and findings indicate more sexuality-related body functioning concerns than appearance concerns in men compared with women (Roy \& Payette, 2012).

There are few studies on the relationship between body image and sexual health in older women and even less among older men. When comparing different age groups (18-29 years, 3049 years, and 50-89 years) of men and women from Australia, Davison and McCabe (2005) found no relationship between body image and sexual satisfaction in women, or in the youngest and oldest groups in men. No association between body image and sexual satisfaction was found in an Israeli study of women and men over 60 years (mean age 73 years) (Shkolnik \& Iecovich, 2013) or in a study of American participants over 55 (mean age 68 years) (Penhollow, Young, \& Denny, 2009). A small bivariate association between body image and sexual satisfaction was found for men in both studies, but body image was not a significant predictor of sexual satisfaction when other relevant variables were entered into the analysis. 


\section{ACCEPTED MANUSCRIPT}

Although there is no significant decrease in body satisfaction in older populations, it is possible that there is a difference between body esteem in general and what is denoted as sexual body esteem. In an interview study of 95 women aged between 20 and 69 years, Montemurro and Gillen (2012) found that the older women were more dissatisfied with their appearance and bodies when evaluated in a sexual or intimate relationship context than in general. In a focus group study (Liechty, 2012), 13 older women (60-69 years) reported that they perceived their bodies more negatively when naked than when clothed.

It is also worth mentioning that there seems to be a positive association between sexual satisfaction and the degree of fitness among older men and women (Marshall, Morris, \& Rainey, 2014). Increasing physical activity might thus be a useful preventive measure in old adulthood, because physical fitness is also related to positive body image and general health (Seguin, Eldridge, Lynch, \& Paul, 2013).

\section{Socio-Cultural Aspects of Sexuality in Older Age}

Attitudes towards aging and towards sexuality in later life vary across cultures (Bancroft, 2009). For example, studies have revealed substantial differences between cultures in how aging and menopause influence women's sexuality and in how the societal role of women influences the impact of aging on their sexuality (Avis et al., 2005; Laumann et al., 2005). The meaning and interpretation of physical changes associated with aging and therefore their impact on sexual functioning are influenced by social values (DeLamater, 2012).

The literature points to three main groups of sociocultural factors: (1) the prevalence, until the 1960s, of a model of sexuality focused on reproduction; (2) sex as a privilege of the young and beautiful; and (3) a demographic asymmetry in later life. 


\section{ACCEPTED MANUSCRIPT}

\section{The longstanding prevalence of a "reproductive" model of sexuality}

Until the approval of oral contraceptives, non-reproductive sexualities were marginalized. In cultures where the primary purpose of sexual intimacy is considered to be reproduction, postmenopausal woman are not expected to be sexually active (Bancroft, 2009). Loss of the ability to reproduce following menopause may contribute to the belief that there is no longer any reason to engage in sexual activity. Thus, social values may result in, or contribute to, the cessation of sexual activity in older persons (DeLamater, 2012). During periods of repressive sexual socialization, myths regarding the sexuality of older people were at the root of negative attitudes that, it can be argued, still persist. The stereotype of older adults as asexual has also been prevalent (Kenny, 2013). Sexual stereotypes regarding older adults are based on societal assumptions about the aging process that are outdated; they persist because ideas that are ingrained in culture take time to change (Kenny, 2013).

DeLamater and Moorman (2007) found an association between attitudes about sexuality and the frequency of partnered sexual behavior. Research has also found that men are more likely than women to rate sex as important (Fisher, 2010). In a survey of 1,384 persons over age 45, negative attitudes toward sex were significant predictors of low sexual desire among men and women (DeLamater \& Sill, 2005), and, apart from age, the effects of attitudes were larger than the effects of other predictors (e.g., illness, medication, having a sexual partner). As a recent review on the sexuality of men and women over age 50 indicated, positive attitudes toward sex in later life and access to a healthy partner are associated with continued sexual activity (DeLamater, 2012). 


\section{ACCEPTED MANUSCRIPT}

\section{Sex as a privilege of the young and beautiful}

Several authors (e.g., Barrett, 2011; DeLamater, 2012; Kenny, 2013; Minichiello et al., 2012) have recently drawn attention to the negative impact of asexual and ageist stereotypes on older people's sexuality. More specifically, pronatalist and youth oriented conceptions of sexuality pervasively perpetuated by the media appear to influence older women more than older men, namely because women experience menopause at around age 51 whilst men remain fertile until later life stages (Alterovits \& Mendelsohn, 2009; Baker, 2005; DeLamater \& Koepsel, 2015; Kenny, 2013; Vares, 2009). Attitudes toward sexuality and aging seem to reflect and endorse a largely "youth-oriented" Western culture. The media bombards us with a plethora of sexual, or sexualized, images, which mainly show and represent young, energetic people. These images may influence not only young people, but also older people's beliefs, and suggest that sex is only for the young and beautiful. Aging men and women may feel they are no longer physically or sexually attractive, undermining their sexual desire, even though their physical capacity has not declined.

\section{Demographic asymmetry in later life}

Another factor that may impact sexuality in older age is demographic asymmetry. In western society there are more women than men over 65 years old, and more women than men without partners, and living in senior residences (DeLamater, 2012). This disparity would be expected to influence the rates of sexual activity in both genders. Differences in relationship status -married, cohabiting, single, divorced, and widowed - are related to differences in incidence and frequency of activity among persons over 50 years of age. Research indicates that relationship or marital status is perhaps the major influence on the frequency of heterosexual 


\section{ACCEPTED MANUSCRIPT}

sexual activity in later life, although the most significant contributor to the decline among women is the increase in the percentage widowed.

A study with a national probability sample of 3005 U.S. adults 57 to 85 years of age revealed a huge gender demographic asymmetry regarding relational status (Lindau et al., 2007). Within the group of 75-85 year olds, $72 \%$ were married men and $18.3 \%$ were widowed men, compared to only $38.4 \%$ married women and $49.8 \%$ widowed (Lindau et all., 2007). Women face the structural barrier to forming new relationships of an increasingly lopsided sex ratio as they age (England \& McClintock, 2009).

\section{Aging and Sexual Satisfaction}

Sexual satisfaction denotes the evaluation of one's sexual life, including both physical and non-physical aspects. The construct has been defined as "an affective response arising from one's subjective evaluation of the positive and negative dimensions associated with one's sexual relationship" (Lawrence \& Byers, 1995, p. 268). Sexual satisfaction has been associated with relationship quality and satisfaction, psychological health, general sense of well-being, happiness and the quality of life (Chao et al., 2011; Dundon \& Rellini, 2010; Wang et al., 2014; Zarpellon Mazo \& Cardoso, 2011). The fact that frequency of sexual contact is highly relevant for sexual satisfaction (Heiman et al., 2011; Kim \& Jeon, 2013; Woloski-Wruble, Oliel, Leefsma, \& Hochner-Celnikier, 2010) and that age-related declining frequency of sexual activity is observed in population-based studies (DeLamater, Hyde, \& Fong, 2008; Lindau et al., 2007; Thompson et al., 2011) prompts questions about the dynamics of sexual satisfaction in older age. The fact that a substantial proportion of older individuals continue to be sexually active into their ' 70 s and '80s (Beckman, Waern, Gustafson, \& Skoog, 2008; Schick et al., 2010; Wang et al., 2014) - men 


\section{ACCEPTED MANUSCRIPT}

more than women (Field et al., 2013; Palacios-Ceña et al., 2012)- makes the question even more salient.

\section{Age-Related Dynamics of Sexual Satisfaction}

As mentioned above, many women and men remain sexually active in their late ' 60 s and '70s and some also in their '80s (Schick et al., 2010). Studies suggest that 40-65\% of men and $25-55 \%$ of women in the 65-75 age group reported being sexually active in the past 12 months (Beckman et al., 2008; Field et al., 2013; Palacios-Ceña et al., 2012), with comparable proportions of aging women and men reporting that sexuality is important to them (Beckman et al., 2008). In the 1971-2001 repeated cross-sectional study of 70 year olds in a large Swedish city, the more recently surveyed participants were more sexually active, indicating a possible cultural change in how older individuals and couples perceive their sexuality (Beckman et al., 2008). Among the reasons for sexual inactivity, aging women often report partner-related factors, particularly the lack of a partner (Beckman et al., 2008; Lindau et al., 2007; Schick et al., 2010), while men tend to attribute their inactivity to personal, health-related reasons (Beckman et al., 2008; Schick et al., 2010).

Several cross-cultural studies have found that sexual satisfaction and overall sexual wellbeing diminish with age (Chao et al., 2011; del Mar Sánchez-Fuentes \& Sierra, 2014; Dijkstra \& Barelds, 2011; Field et al., 2013; Graf \& Patrick, 2014; McFarland, Uecker, \& Regnerus, 2011; Schick et al., 2010; Træen \& Schaller, 2010). However, some studies, have failed to replicate these finding, pointing to the importance of studying both biological and sociocultural mechanisms underlying the negative association between age and sexual satisfaction (Neto \& Pinto, 2012; Thompson et al., 2011). Another consistent finding is that aging men report higher 


\section{ACCEPTED MANUSCRIPT}

levels of sexual satisfaction and sexual well-being than aging women (Kim \& Jeon, 2013; Laumann et al., 2006; McFarland et al., 2011; Træen \& Schaller, 2010).

Self-perceived reasons for diminished sexual satisfaction have rarely been addressed. In a U.S. national probability survey among 3,377 men and women aged 62-90, a substantial proportion of respondents (41\%), particularly men and women in their ' 80 s, reported that their partners do pleasant "nonsexual things before having sex" somewhat or much less often than they would have liked (Galinsky, McClintock, \& Waite, 2014). Among those who had sexual intercourse in the past 12 months, a fifth of women and a quarter of men reported that sexual foreplay was "somewhat or much less frequent" than they would have liked.

Considering that aging women's sexual activity, compared to that of aging men, seems to be more dependent on partner's health and availability, the evidence that the association between gender and sexual satisfaction is moderated by relationship-related factors is not surprising. For example, a Californian study that sampled only partnered men and women found no significant gender difference in satisfaction with one's sex life (Wang et al., 2014). Similarly, the large-scale national probability survey of 62-90 year olds mentioned above found no difference in the proportion of partnered men and women who rejected the notion that their "sex life is lacking in quality" (Galinsky et al., 2014). In a five-country study of sexual and relationship satisfaction, sexual satisfaction was higher among women in long-duration relationships (25+ years) than men (Heiman et al., 2011).

Despite the age-specific dynamics of sexual satisfaction and sexual well-being, substantial proportions of aging men and women are reportedly satisfied with their sex life. In the most recent wave of the large-scale British National Survey of Sexual Attitudes and 


\section{ACCEPTED MANUSCRIPT}

Lifestyles (NATSAL-3), 54\% of male and 49\% of female respondents aged 65-74 years reported satisfaction with their sex lives (Field et al., 2013). In a recent community-based survey of Californian women and men with a mean age of 75 years, $41 \%$ of men and $36 \%$ of women were very satisfied with their sex lives (Wang et al., 2014).

In the repeated cross-sectional Swedish study (Beckman et al., 2008), the proportion of highly sexually satisfied 70 year olds was significantly higher in the 2000/1 than in the 1976/7 wave. Interestingly, the change was larger among aging women. The proportion of highly satisfied women increased from $41 \%$ in $1976 / 7$ to $62 \%$ in $2000 / 1$; the respective proportions among men were $58 \%$ and $71 \%$.

\section{Predictors and Correlates of Sexual Satisfaction in Older Age}

Several studies assessed the predictors and correlates of sexual satisfaction among aging men and women. As mentioned earlier, gender has consistently been found to significantly predict sexual satisfaction levels (del Mar Sánchez-Fuentes \& Sierra, 2014; McFarland et al., 2011; Syme, Klonoff, Macera, \& Brodine, 2013), and age (Dijkstra \& Barelds, 2011; McCallHosenfeld et al., 2008; Træen \& Schaller, 2010). Although it appears that the negative association between age and sexual satisfaction, which is usually small in size, is not linear (del Mar Sánchez-Fuentes \& Sierra, 2014; Thompson et al., 2011), more research is needed to better understand the dynamics of sexual satisfaction in older individuals and couples. Similarly, little is currently known about women's higher vulnerability to sexual dissatisfaction — beyond their lower likelihood of being partnered, compared to men.

Older age can affect sexual satisfaction in diverse ways. At least three different levels of interaction between aging and sexual satisfaction may be distinguished: the person-based, 


\section{ACCEPTED MANUSCRIPT}

interpersonal, and culture-related levels and their specific factors. The accumulating evidence about the correlates of sexual satisfaction in aging men and women enables a solid understanding of the first level factors, a well-informed approach to the second level factors, but only fragmentary insights into the factors and mechanisms operating at the third level.

Research points to two important domains of the person-based level. The first, healthrelated dimension, which includes general health status, mental and sexual health issues, has been consistently associated with sexual satisfaction in aging men and/or women (de Vries, 2015; Lindau et al., 2007; Scott, Sandberg, Harper, \& Miller, 2012). Chronic illnesses such as diabetes, cardiovascular problems, arthritis and fatigue have been implicated as the core of physical health problems affecting sexual satisfaction (DeLamater et al., 2008; Field et al., 2013; Syme et al., 2013). Similar empirical support has been obtained for the importance of mental health problems, particularly those related to depression and anti-depressant medication use (Dundon \& Rellini, 2010; Kim \& Jeon, 2013; McCall-Hosenfeld et al., 2008; Scott et al., 2012; Thompson et al., 2011; Wang et al., 2014). Finally, moderate to strong associations between sexual satisfaction and well-being, and sexual health disorders or impaired sexual function (Ratner, Erekson, Minkin, \& Foran-Tuller, 2011) have been consistently observed (Heiman et al., 2011; Laumann et al., 2006; Træen \& Schaller, 2010). In addition to relatively frequent agerelated loss of sexual interest in both men and women (DeLamater et al., 2008), erectile problems among men and problems with lubrication, genital pain, and diminished orgasmic function were frequently found to negatively affect sexual satisfaction in older age (Field et al., 2013; Heiman et al., 2011; Laumann et al., 2006). Taking into account the reported associations between sexual and mental health disorders, impaired sexual function can not only directly affect 


\section{ACCEPTED MANUSCRIPT}

aging individuals' and couples' sexual well-being directly but can also indirectly influence wellbeing, through an increased vulnerability to mood disorders (Field et al., 2013).

The other person-related dimension entails personal attitudes toward and beliefs about sexuality in older age, body image issues, and other cognitive and emotional reactions to the lifecourse dynamics of sexuality. Several quantitative and qualitative studies reported that the factors associated with this dimension were significantly associated with, or highly relevant to, sexual satisfaction. For example, in an online sample of adults aged 45-74 years (mean age 54 years), age-related attitudes toward sex, and not gender, were significantly correlated with sexual well-being (Graf \& Patrick, 2014). Similar findings were reported in an online survey of middleaged and older adults which used the Aging Sexuality Knowledge and Attitudes Scale (Graf \& Patrick, 2014). A significant contribution of attitudes toward sexuality in older age was also reported in the Global Study of Sexual Attitudes and Behaviors (Laumann et al., 2006). Tapping into internalized social roles and expectations, an ethnographic study carried out among 40 Japanese men and women over the age of 60 focused on gender-specific interpretations of the importance of sexuality in older age (Moore, 2010). Although rarely addressed among older adults, body image — which has been repeatedly found important for younger women's sexual satisfaction—does not seem to be a substantial issue for aging women (Dundon \& Rellini, 2010; Tiggemann \& McCourt, 2013).

The interpersonal level has been explored in several studies. Frequency of sex has been associated with sexual satisfaction among both men and women (Heiman et al., 2011; WoloskiWruble et al., 2010). Aside from partner availability - a highly relevant issue for many older women - research has pointed to the role of poor spousal health (Syme et al., 2013), partner's 


\section{ACCEPTED MANUSCRIPT}

lack of interest in sex (DeLamater et al., 2008), and relationship or marital quality (DeLamater et al., 2008; Dundon \& Rellini, 2010; Kim \& Jeon, 2013), including spousal support (McFarland et al., 2011). In the Wisconsin Longitudinal Study (DeLamater et al., 2008), satisfaction with one's relationship or marriage was the strongest predictor of participants' satisfaction with their sexual relationship. Similarly, in a clinical sample of 86 women aged 40-70 years, relationship-related indicators were stronger predictors of sexual satisfaction than sexual function (Dundon \& Rellini, 2010). The importance of relationship quality was indirectly corroborated in a crosscultural study that found physical intimacy a significant correlate of sexual satisfaction regardless of gender (Heiman et al., 2011). In another study of older married couples, partner communication problems fully mediated the association between depression and sexual satisfaction, as well as the relationship between general health and sexual satisfaction (Scott et al., 2012). The findings held for both male and female participants.

\section{Limitations}

Regarding the literature on sexual satisfaction, several limitations and gaps were noted, with one of the most prominent concerns involving a lack of research on sexual satisfaction among aging LGBT individuals and couples (de Vries, 2007). Considering that LGBT individuals increasingly have access to and choose to participate in civil partnerships and marriage in the Western world, this oversight will hopefully be amended in the near future. Our search strategy was limited to articles published only in English which means that important articles regarding the topic of this review where English was not the primary language were not included. 


\section{ACCEPTED MANUSCRIPT}

\section{Conclusions and Directions for Future Research}

Methodologically, large variability was found in the measurement of sexual satisfaction, with one- to three-item measures (often defining satisfaction in terms of sexual frequency, and only sometimes including emotional and physical satisfaction with one's sexual life) prevailing over more elaborate and multi-dimensional scales. Further limiting comparisons, some studies assessed the more general notion of sexual well-being: e.g., by adding an item about the "importance of sex" rather than sexual satisfaction. The lack of systematic validation and consistent approaches to the measurement of sexual satisfaction measures is further confounded by the fact that the weight and nature of the components and dimensions of sexual satisfaction may differ for younger and older adults. More research is needed on what constitutes, and influences, sexual satisfaction in aging men and women.

There is surprisingly little evidence about the relationship between religiosity and sexual satisfaction in older age (McFarland et al., 2011). Given the importance attached to sexuality in religious teachings, which often place a strong emphasis on the procreative purpose of sex, such lack of attention to this specific type of social norms should be rectified.

There also is a need for more cross-cultural research on aging and sexual satisfaction. In contrast to studies focused on the person-based and interpersonal levels, the factors and mechanisms representing the culture-related level largely remain unknown. Conceptually, this dimension can be divided into situational and structural factors. The first address aging individuals' social roles and lifestyles e.g., grandparents' involvement in childcare, the lack of intimacy in foster homes and other institutions for elderly, etc., while structural factors primarily refer to the social regulation of aging people's sexuality. This process operates mainly through 


\section{ACCEPTED MANUSCRIPT}

societal norms and collective beliefs, which tend to present de-sexualization as a normative part of the process of aging - stigmatizing, in consequence, those who continue to be sexually motivated and active despite their older age. Apart from the finding from the Global Study of Sexual Attitudes and Behaviors (Laumann et al., 2006) that sexual well-being is higher in societies characterized by more gender equality, no systematic assessment of the effects of societal norms on sexual satisfaction in older age has been attempted.

While increasingly defined by diversity and multicultural influences, western society faces difficulties that include culture-specific variability in openness about sexual, and genderrelated dynamics and processes. Research on sexual function and satisfaction among aging men and women will require cultural sensitivity, interdisciplinary collaboration, and open exploration of the most appropriate methodological approaches (including ethnographic explorations). A number of topics should be considered for future comparative studies, including the influence of socioeconomic conditions, the role of religion, the contribution of social capital and lifestyle characteristics, the influence of mass media, and the availability of sexual health services for aging individuals and couples of different ethnic, religious, and cultural backgrounds.

Finally, more research is need on the sociocultural aspects of sexuality in later life in the modern context of positive and successful aging, where sexuality is positioned as a key element. Sexuality in later life has shifted over recent years from conceptualizations of older people as asexual to the "sexy oldie" (Gott, 2005). 


\section{ACCEPTED MANUSCRIPT}

\section{References}

Alterovits, S., \& Mendelsohn, G. (2009). Partner preferences across the life span: Online dating by older adults. Psychology and Aging. 24(2), 513-517.

Avis, N. E., Zhao, X., Johannes, C. B., Ory, M., Brockwell, S., \& Greendale, G. (2005).

Correlates of sexual function among multi-ethnic middle-aged women: Results from the Study of Women's Health Across the Nation (SWAN). Menopause, 12, 385-398.

Baker, M. (2005). Medically assisted conception: Revolutionizing family or perpetuating a nuclear and gendered model? Journal of Comparative Family Studies, 36, 521-543.

Bancroft, J. (2009). Sexuality and ageing. In J. Bancroft, Human sexuality and its problems (3rd ed., pp. 238-252). New York: Elsevier.

Barrett, C. M. (2011). Auditing organisational capacity to promote the sexual health of older people. Sensoria: A Journal of Mind, Brain \& Culture, 7(1), 31-36.

Beckman, N., Waern, M., Gustafson, D., \& Skoog, I. (2008). Secular trends in self reported sexual activity and satisfaction in Swedish 70 year olds: Cross sectional survey of four populations, 1971-2001. BMJ, 337, a279.

Brody, S. (2010). The relative health benefits of different sexual activities. Journal of Sexual Medicine, 7 (4), 1336-1361.

Byers, E. S. (2005). Relationship satisfaction and sexual satisfaction: A longitudinal study of individuals in long-term relationships. Journal of Sex Research, 42, 113-118. 


\section{ACCEPTED MANUSCRIPT}

Cash, T. F. (2004). Cognitive-behavioral perspectives on body image. In T. F. Cash \& T.

Pruzinsky (Eds.), A handbook of theory, research, \& clinical practice (pp. 38-46). New York: Guilford Press.

Chao, J.-K., Lin, Y.-C., Ma, M.-C., Lai, C.-J., Ku, Y.-C., Kuo, W.-H., \& Chao, I.-C. (2011). Relationship among sexual desire, sexual satisfaction, and quality of life in middle-aged and older adults. Journal of Sex \& Marital Therapy, 37(5), 386-403.

doi:10.1080/0092623X.2011.607051

Claudat, K., \& Warren, C. S. (2014). Self-objectification, body self-consciousness during sexual activities, and sexual satisfaction in college women. Body Image, 11(4), 509-515.

doi:http://dx.doi.org/10.1016/j.bodyim.2014.07.006

Davison, T., \& McCabe, M. (2005). Relationships between men's and women's body image and their psychological, social, and sexual functioning. Sex Roles, 52(7-8), 463-475.

doi:10.1007/s11199-005-3712-Z

Davison, S. L. et al. (2009). The relationship between self-reported sexual satisfaction and general well-being in women. Journal of Sexual Medicine, 6(10), 2690-2697.

de Vries, B. (2007). LGBT couples in later life: A study in diversity. Generations, 31(3), 18-23.

de Vries, B. (2015). Aging and sexuality. In P. Whelehan \& A. Bolin (Eds.), International Encyclopedia of Human Sexuality (pp. 49-51). Wiley-Blackwell: Hoboken.

del Mar Sánchez-Fuentes, M., \& Sierra, J. C. (2014). Sexual satisfaction in a heterosexual and homosexual Spanish sample: The role of socio-demographic characteristics, health indicators, 


\section{ACCEPTED MANUSCRIPT}

and relational factors. Sexual and Relationship Therapy, 30(2), 226-242.

doi:10.1080/14681994.2014.978275

DeLamater, J. (2012). Sexual expression in later life: A review and synthesis. Journal of Sex Research, 49, 125-141.

DeLamater, J., \& Sill, M. (2005). Sexual desire in later life. Journal of Sex Research, 42, 138149.

DeLamater, J., \& Moorman, S. (2007). Sexual behavior in later life. Journal of Aging and Health, 19, 921-945.

DeLamater, J., Hyde, J. S., \& Fong, M.-C. (2008). Sexual satisfaction in the seventh decade of life. Journal of Sex \& Marital Therapy, 34(5), 439-54. doi:10.1080/00926230802156251

DeLamater, J., \& Karraker, A. (2009). Sexual functioning in older adults. Current Psychiatry Reports, 11, 6-11.

DeLamater, J., \& Koepsel, E. (2015). Relationships and sexual expression in later life: a biopsychosocial perspective. Sexual and Relationship Therapy, 30(1), 37-59.

Dijkstra, P., \& Barelds, D. P. H. (2011). Women, sex and modern society: The sex lives of readers of a Dutch women's magazine. International Journal of Sexual Health, 23(1), 35-47.

Dundon, C. M., \& Rellini, A. H. (2010). More than sexual function: Predictors of sexual satisfaction in a sample of women age 40-70. Journal of Sexual Medicine, 7(2 PART 2), 896904. doi:10.1111/j.1743-6109.2009.01557.x 


\section{ACCEPTED MANUSCRIPT}

England, P., \& McClintock, E. (2009). The gendered double standard of aging in US marriage markets. Population and Development Review, 35, 797-816.

Field, N., Mercer, C. H., Sonnenberg, P., Tanton, C., Clifton, S., Mitchell, K. R., ... Johnson, A. M. (2013). Associations between health and sexual lifestyles in Britain: Findings from the third National Survey of Sexual Attitudes and Lifestyles (Natsal-3). Lancet, 382(9907), 1830-1844. doi:10.1016/S0140-6736(13)62222-9

Fisher, L. (2010). Sex, romance and relationships: AARP survey of midlife and older adults.(AARP Pub. No. D19234). Washington DC: AARP.

Gagne, D. A., Von Holle, A., Brownley, K. A., Runfola, C. D., Hofmeier, S., Branch, K. E., \& Bulik, C. M. (2012). Eating disorder symptoms and weight and shape concerns in a large webbased convenience sample of women ages 50 and above: results of the Gender and Body Image (GABI) study. International Journal of Eating Disorders, 45(7), 832-844. doi:10.1002/eat.22030

Galinsky, A. M., McClintock, M. K., \& Waite, L. J. (2014). Sexuality and physical contact in National Social Life, Health, and Aging Project Wave 2. Journals of Gerontology. Series B: Psychological Sciences and Social Ciences, 69(Suppl 2), S83-98. doi:10.1093/geronb/gbu072

Gott, M. (2005). Sexuality, sexual health and ageing. Buckingham, England: Open University Press.

Graf, A. S., \& Patrick, J. H. (2014). The influence of sexual attitudes on mid- to late-life sexual well-being: Age, not gender, as a salient factor. International Journal of Aging and Human Development, 79(1), 55-79. doi:10.2190/AG.79.1.c 


\section{ACCEPTED MANUSCRIPT}

Grant, M. J., \& Booth, A. (2009). A typology of reviews: an analysis of 14 review types and associated methodologies. Health Information and Libraries Journal, 266, 91-108. doi: $10.1111 / \mathrm{j} .1471-1842.2009 .00848 . \mathrm{x}$

Graugaard, C., Pedersen, B. K., \& Frisch, M. (2012). Seksualitet og sundhed. Copenhagen: Vidensråd for Forebyggelse.

Grogan, S. (2008). Body image: understanding body dissatisfaction in men, women, and children. London: Routledge.

Heiman, J. R., Long, J. S., Smith, S. N., Fisher, W. A., Sand, M. S., \& Rosen, R. C. (2011). Sexual satisfaction and relationship happiness in midlife and older couples in five countries. Archives of Sexual Behavior, 40(4), 741-753. doi:10.1007/s10508-010-9703-3

Hurd Clarke, L., \& Korotchenko, A. (2011). Aging and the body: A review. Canadian Journal on Aging, 30(3), 495-510. doi:10.1353/cja.2011.0035

Hurd Clark, L. (2000). Older women's body image and embodied experience: An exploration. Journal of Women \& Aging, 12(3-4), 77-97. doi:10.1300/J074v12n03_06

Jannini, E. A., Fisher, W.A., Bitzer, J., \& McMahon, C. G. (2009). Is sex just fun? How sexual activity improves health. Journal of Sexual Medicine 6(10), 2640-2648.

Kenny, R. (2013). A review of the literature on sexual development of older adults in relation to the asexual stereotype of older adults. Canadian Journal of Family and Youth, 5(1), 91-106. 


\section{ACCEPTED MANUSCRIPT}

Kim, O., \& Jeon, H. O. (2013). Gender differences in factors influencing sexual satisfaction in Korean older adults. Archives of Gerontology and Geriatrics, 56(2), 321-6. doi:10.1016/j.archger.2012.10.009

Kontula, O., \& Haavio-Mannila, E. (2009). The impact of aging on human sexual activity and sexual desire. Journal of Sex Research, 42, 46-46.

Laumann, E. O., Nicolosi, A., Glasser, D. B., Paik, A., Gingell, C, Moreira, E., \& Wang, T. for the GSSAB Investigators' Group (2005). Sexual problems among women and men aged 40-80 years: Prevalence and correlates identified in the Global Study of Sexual Attitudes and Behaviors. International Journal of Impotence Research, 17, 39-57.

Laumann, E. O., Paik, A., Glasser, D. B., Kang, J.-H., Wang, T., Levinson, B., ... Gingell, C. (2006). A cross-national study of subjective sexual well-being among older women and men: Findings from the Global Study of Sexual Attitudes and Behaviors. Archives of Sexual Behavior, 35(2), 145-61. doi:10.1007/s10508-005-9005-3

Lawrance, K., \& Byers, E. S. (1995). Sexual satisfaction in long-term heterosexual relationships: The interpersonal exchange model of sexual satisfaction. Personal Relationships, 2(4), 267-285. doi:10.1111/j.1475-6811.1995.tb00092.x

Liechty, T. (2012). "Yes, I worry about my weight... but for the most part I'm content with my body": Older women's body dissatisfaction alongside contentment. Journal of Women \& Aging, 24(1), 70-88. doi:10.1080/08952841.2012.638873 


\section{ACCEPTED MANUSCRIPT}

Lindau, S. T., Schumm, L. P., Laumann, E. O., Levinson, W., O’Muircheartaigh, C. A, \& Waite, L. J. (2007). A study of sexuality and health among older adults in the United States. New England Journal of Medicine, 357(8), 762-774. doi:10.1056/NEJMoa067423

Lindau, S. T., \& Gavrilova, N. (2010). Sex, health, and years of sexually active life gained due to good health: evidence from two US population based cross sectional surveys of ageing. British Medical Journal, 340, 1-11.

Marshall, A., Morris, D., \& Rainey, J. (2014, September 23). Linking exercise and sexual satisfaction among healthy adults. Electronic Journal of Human Sexuality, 17. http://www.ejhs.org/volume17/exercise.html

McCall-Hosenfeld, J. S., Jaramillo, S. A., Legault, C., Freund, K. M., Cochrane, B. B., Manson, J. E., ... Bonds, D. (2008). Correlates of sexual satisfaction among sexually active postmenopausal women in the Women's Health Initiative-Observational Study. Journal of General Internal Medicine, 23(12), 2000-9. doi:10.1007/s11606-008-0820-9

McFarland, M. J., Uecker, J. E., \& Regnerus, M. D. (2011). The role of religion in shaping sexual frequency and satisfaction: evidence from married and unmarried older adults. Journal of Sex Research, 48(2-3), 297-308. doi:10.1080/00224491003739993

Minichiello, V., Rahman, S., Hawkes, G., \& Pitts, M. (2012). STI epidemiology in the global older population: emerging challenges. Perspectives in Public Health, 132(4), 178-181. 


\section{ACCEPTED MANUSCRIPT}

Montemurro, B., \& Gillen, M. M. (2012). Wrinkles and sagging flesh: Exploring transformations in women's sexual body image. Journal of Women \& Aging, 25(1), 3-23.

doi:10.1080/08952841.2012.720179

Moore, K. L. (2010). Sexuality and sense of self in later life: Japanese men's and women's reflections on sex and aging. Journal of Cross-Cultural Gerontology, 25(2), 149-63. doi:10.1007/s10823-010-9115-9

Neto, F., \& Pinto, M. D. C. (2012). The satisfaction with sex life across the adult life span. Social Indicators Research, 114(3), 767-784. doi:10.1007/s11205-012-0181-y

Palacios-Ceña, D., Carrasco-Garrido, P., Hernández-Barrera, V., Alonso-Blanco, C., JiménezGarcía, R., \& Fernández-de-las-Peñas, C. (2012). Sexual behaviors among older adults in Spain: Results from a population-based national sexual health survey. Journal of Sexual Medicine, 9(1), 121-129. doi:10.1111/j.1743-6109.2011.02511.x

Pearce, G., Thøgersen-Ntoumani, C., \& Duda, J. (2013). Body image during the menopausal transition: a systematic scoping review. Health Psychology Review, 8(4), 473-489. doi:10.1080/17437199.2013.848408

Penhollow, T. M., Young, M., \& Denny, G. (2009). Predictors of quality of life, sexual intercourse, and sexual satisfaction among active older adults. American Journal of Health Education, 40(1), 14-22. doi:10.1080/19325037.2009.10599074 


\section{ACCEPTED MANUSCRIPT}

Ratner, E. S., Erekson, E. A., Minkin, M. J., \& Foran-Tuller, K. A. (2011). Sexual satisfaction in the elderly female population: A special focus on women with gynecologic pathology. Maturitas, 70(3), 210-5. doi:10.1016/j.maturitas.2011.07.015

Rodin, J., Silberstein, L., \& Striegel-Moore, R. (1984). Women and weight: A normative discontent. Nebraska Symposium on Motivation, 32, 267-307.

Rosen, R. C., Heiman, J. R., Long, J. S., Fisher, W. A., \& Sand, M. S. (2015). Men with sexual problems and their partners: Findings from the International Survey of Relationships. Archives of Sexual Behavior, 45, (1) 159-173..

Roy, M., \& Payette, H. (2012). The body image construct among Western seniors: A systematic review of the literature. Archives of Gerontology and Geriatrics, 55(3), 505-521. doi:http://dx.doi.org/10.1016/j.archger.2012.04.007

Schick, V., Herbenick, D., Reece, M., Sanders, S. A., Dodge, B., Middlebstadt, S. E., \& Fortenberry, J. D. (2010). Sexual behaviors, condom use, and sexual health of Americans over 50: Implications for sexual health promotion for older adults. Journal of Sexual Medicine, 7 Suppl 5, 315-29. doi:10.1111/j.1743-6109.2010.02013.x

Schmidt, G., \& Matthiesen, S. (2003). Spätmoderne 60-Jährige. In Redaktion FORUM (eds), Alter und sexualität. Frankfurt: BzgA FORUM, pp. 16-24.

Scott, V. C., Sandberg, J. G., Harper, J. M., \& Miller, R. B. (2012). The impact of depressive symptoms and health on sexual satisfaction for older couples: Implications for clinicians. Contemporary Family Therapy, 34(3), 376-390. doi:10.1007/s10591-012-9198-2 


\section{ACCEPTED MANUSCRIPT}

Seguin, R. A., Eldridge, G., Lynch, W., \& Paul, L. C. (2013). Strength training improves body image and physical activity behaviors among midlife and older rural women. Journal of Extension, 51(4), 4FEA2. Retrieved from

http://www.joe.org/joe/2013august/pdf/JOE_v51_4a2.pdf

Shkolnik, D., \& lecovich, E. (2013). Health, body image, gender, and migration status:

Their relationship to sexuality in old age. International Psychogeriatrics, 25(10), 1717

-1727. doi: http://dx.doi.org/10.1017/S1041610213000604

Slagsvold, B., \& Strand, N. P. (2005). Morgendagens eldre - blir de mer kravstore og mindre beskjedne? [Tomorrow's older adults - are they becoming more demanding and less modest?] In Slagsvold B, Solem PE (Eds.), Morgendagens eldre. En sammenligning av verdier, holdninger og atferd blant dagens middelaldrende og eldre [Tomorrow's older adults. A comparison of values, attitudes and behaviour among today's middle aged and older citizens]. Oslo: NOVA report no 11 .

Syme, M. L., Klonoff, E. A., Macera, C. A., \& Brodine, S. K. (2013). Predicting sexual decline and dissatisfaction among older adults: The role of partnered and individual physical and mental health factors. Journals of Gerontology. Series B: Psychological Sciences and Social Sciences, 68(3), 323-32. doi:10.1093/geronb/gbs087

Syme, M. L. (2014). The evolving concept of older adult sexual behavior and its benefits. Generations, 38 (1), 35-41. 


\section{ACCEPTED MANUSCRIPT}

The Norwegian Knowledge Centre for the Health Services (2016). Retried February $16^{\text {th }}$ from http://www.kunnskapssenteret.no/verktoy/slik-oppsummerer-vi-forskning

Thompson, W. K., Charo, L., Vahia, I. V, Depp, C., Allison, M., \& Jeste, D. V. (2011). Association between higher levels of sexual function, activity, and satisfaction and self-rated successful aging in older postmenopausal women. Journal of the American Geriatrics Society, 59(8), 1503-8. doi:10.1111/j.1532-5415.2011.03495.x

Tiggemann, M., \& McCourt, A. (2013). Body appreciation in adult women: Relationships with age and body satisfaction. Body Image, 10(4), 624-7. doi:10.1016/j.bodyim.2013.07.003

Træen, B., \& Schaller, S. (2010). Subjective sexual well-being in a Web sample of heterosexual Norwegians. International Journal of Sexual Health, 22(3), 180-194. doi:10.1080/19317611003776087

Vares, T. (2009). Reading the 'sexy oldie': Gender, age(ing) and embodiment. Sexualities, 12(4), 503-524.

Wang, V., Depp, C. a., Ceglowski, J., Thompson, W. K., Rock, D., \& Jeste, D. V. (2014). Sexual health and function in later life: A population-based study of 606 older adults with a partner. American Journal of Geriatric Psychiatry, 23(3), 227-233. doi:10.1016/j.jagp.2014.03.006

WAS Declaration of Sexual Rights (1999). See http://www.worldsexology.org/resources/declaration-of-sexual-rights/ 


\section{ACCEPTED MANUSCRIPT}

Woertman, L., \& van den Brink, F. (2012). Body image and female sexual functioning and behavior: A review. The Journal of Sex Research, 49(2-3), 184-211.

doi:10.1080/00224499.2012.658586

Woloski-Wruble, A. C., Oliel, Y., Leefsma, M., \& Hochner-Celnikier, D. (2010). Sexual activities, sexual and life satisfaction, and successful aging in women. Journal of Sexual Medicine, 7(7), 2401-10. doi:10.1111/j.1743-6109.2010.01747.x

Zarpellon Mazo, G., \& Cardoso, F. L. (2011). Sexual satisfaction and correlates among elderly Brazilians. Archives of Gerontology and Geriatrics, 52(2), 223-227.

doi:10.1016/j.archger.2010.03.024 